\title{
Circulating Endocannabinoids and Mortality in Hemodialysis Patients
}

\author{
Hamid Moradi a, c Christina Park ${ }^{a}$ Elani Strejaa, c Donovan A. Argueta ${ }^{d}$ \\ Nicholas V. DiPatrizio ${ }^{d}$ Amy S. You ${ }^{a}$ Connie M. Rhee ${ }^{a}$ Nosratola D. Vaziria \\ Kamyar Kalantar-Zadeh ${ }^{\mathrm{a}, \mathrm{c}}$ Daniele Piomelli ${ }^{\mathrm{b}}$ \\ a Division of Nephrology, Hypertension and Kidney Transplantation, University of California Irvine School of \\ Medicine, Irvine, CA, USA; ${ }^{\mathrm{b}}$ Anatomy and Neurobiology, University of California Irvine School of Medicine, Irvine, CA, \\ USA; ${ }^{C}$ Tibor Rubin VA Medical Center, Nephrology Section, Long Beach, CA, USA; ${ }^{\mathrm{d}}$ Division of Biomedical Sciences, \\ University of California Riverside School of Medicine, Riverside, CA, USA
}

\section{Keywords \\ End stage renal disease - Hemodialysis · Mortality . \\ Endocannabinoid - Endocannabinoid system . \\ 2-arachidonoylglycerol · Anandamide}

\begin{abstract}
Background: Mortality in patients with end-stage renal disease (ESRD) on maintenance hemodialysis (MHD) remains exceptionally high. While traditional risk factors such as obesity are paradoxically associated with better survival, nontraditional risk factors including cachexia increase the likelihood of poor outcomes. There is accumulating evidence that the endocannabinoid (ECB) system plays a major role in energy preservation and storage, factors which can prevent the deleterious effects of cachexia. Hence, in this study, we evaluated the association of circulating ECB levels with mortality in MHD patients. Methods: Serum concentrations of anandamide (AEA) and 2-arachidonoyl-sn-glycerol (2-AG), major ECB ligands, were measured in MHD patients. Their correlation with various clinical/laboratory indices and association with 12-month all-cause mortality were examined. Results: Serum 2-AG levels positively correlated with body mass index, serum triglycerides and body anthropometric
\end{abstract}

measures. Meanwhile, serum AEA levels correlated positively with serum interleukin-6, and negatively with serum very low-density lipoprotein levels. While increased serum 2-AG levels were associated with reduced risk of all-cause mortality (hazard ratio $[\mathrm{HR}] 0.52,95 \% \mathrm{Cl} 0.28-0.98$ ), there was no clear association between serum AEA levels and mortality (HR 0.91, 95\% Cl 0.48-1.72). Conclusions: In MHD patients, the circulating levels of ECB ligand, 2-AG, may play an important role in determining body mass and risk of mortality. These observations were unique to 2-AG as similar findings were not obtained with serum AEA. Future studies need to investigate the mechanisms responsible for these associations and examine the modulation of the ECB system as a potential target for therapy in ESRD.

$$
\begin{aligned}
& \text { (c) } 2020 \text { The Author(s) } \\
& \text { Published by S. Karger AG, Basel }
\end{aligned}
$$

\section{Introduction}

The prevalence of end-stage renal disease (ESRD) continues to increase in the United States with recent projections estimating that by 2030 there will $>970,000$ patients with ESRD requiring renal replacement therapy including maintenance hemodialysis (MHD) [1-4]. Patients on

\begin{tabular}{ll}
\hline KARGER & $\begin{array}{l}\text { (c) } 2020 \text { The Author(s) } \\
\text { Published by S. Karger AG, Basel }\end{array}$ \\
E-Mail karger@karger.com & This article is licensed under the Creative Commons Attribution- \\
www.karger.com/ajn & $\begin{array}{l}\text { NonCommercial-NoDerivatives 4.0 International License (CC BY- } \\
\text { NC-ND) (http://www.karger.com/Services/OpenAccessLicense). } \\
\text { Usage and distribution for commercial purposes as well as any dis- } \\
\text { tribution of modified material requires written permission. }\end{array}$
\end{tabular}

Hamid Moradi, MD

Veterans Affairs Long Beach Healthcare System

5901 East 7th Street

Long Beach, CA 90822 (USA)

E-Mail hamid.moradi@va.gov 
MHD experience a significantly increased risk of death and treatment of traditional risk factors such as hyperlipidemia is not necessarily associated with improved outcomes in this patient population $[5,6]$. In fact, the presence of certain traditional risk factors including obesity and hypertriglyceridemia can be paradoxically associated with better survival [7-10], whereas nontraditional risk factors such as inefficient energy metabolism as manifested by protein energy wasting (PEW) and cachexia increase the risk for worse outcomes $[8,11,12]$. It is well known that ESRD is associated with a catabolic state marked by increased basal energy expenditure, which leads to the wasting of adipose tissue and skeletal muscle (i.e., cachexia) [11-13] and poor outcomes including a significantly higher risk of death $[11,14,15]$.

In this context, one promising area that has not been fully explored is the role of the endocannabinoid (ECB) system in ESRD-associated cachexia and mortality. It is well-established that the ECB system plays an important role in energy metabolism $[16,17]$. The latter effects are mediated via central and peripheral mechanisms relying on activation of specific $G$ protein-coupled receptors, cannabinoid-1 $\left(\mathrm{CB}_{1} \mathrm{R}\right)$ and cannabinoid-2, by endogenous lipid-derived ligands (ECBs). Anandamide (also known as $\mathrm{N}$-arachidonoylethanolamine or AEA) and 2-arachidonoyl-sn-glycerol (2-AG) are the most comprehensively studied ECB ligands and significant levels of these lipid-derived mediators have been found in the circulation as well as most organs including the brain, liver, and adipocytes [17-20]. The activation of the ECB system (mainly via $\mathrm{CB}_{1} \mathrm{R}$ activation) leads to an increased intake of energy-rich foods, decreased energy expenditure by inhibition of brown adipose tissue activity, and stimulation of energy storage via lipogenesis and white adipose tissue formation $[20,21]$. Overactivity of the ECB system has been demonstrated to play a causal role in pathogenesis of obesity, hypertriglyceridemia and metabolic syndrome and there is accumulating evidence that obesity and metabolic syndrome are associated with significant elevations of circulating ECBs [22-24]. Conversely, pharmacological antagonists of $\mathrm{CB}_{1} \mathrm{R}$ have been shown to decrease body weight and improve metabolic profile in obese animals and humans [20,25-27]. While the role of the ECB system in the pathogenesis of obesity and metabolic syndrome has been well-described, its potential alterations and utility as a therapeutic target in the context of cachexia and wasting has been less studied. This is especially significant in conditions where PEW and cachexia can make an important contribution to the risk of morbidity and mortality such as ESRD. We recently found significant circulating levels of 2-AG in serum of patients on hemodialysis [28]. Serum levels of 2-AG positively correlated with serum triglycerides and markers of body mass [28]. However, given the small sample size of studies which have evaluated circulating ECBs, the association of serum levels of these mediators with clinical endpoints including mortality is lacking.

In light of our recent findings and given the association of ESRD with abnormal energy metabolism and PEW and the role of ECB system in energy homeostasis, we sought to further evaluate the association of circulating ECB levels with laboratory and clinical outcomes including all-cause mortality in a large sample of patients on hemodialysis.

\section{Methods}

\section{Study Population}

We identified a random subcohort of MHD adult patients actively participating in the ongoing, prospective Malnutrition, Diet and Racial Disparities in Chronic Kidney Disease (MADRAD) study (ClinicalTrials.gov, NCT01415570) between 2012 and 2015. In the MADRAD study, differences in dietary factors and nutritional status are examined across racial and ethnic groups of MHD patients receiving treatment in outpatient dialysis facilities in the Southern California region [29].

There were 523 unique patients who were enrolled in MADRAD and had a blood measurement taken between October 2013 and 2015. Among these patients, we pulled 450 random samples for analysis. After removing patient samples with measurement errors due to the extraction process or sample loss, 400 and $436 \mathrm{MHD}$ patients had data available to analyze serum 2-AG and AEA respectively.

This study was approved by the Institutional Review Committees of the Los Angeles Biomedical Research Institute at HarborUCLA, Torrance, CA, USA, and the University of California, Irvine Medical Center, Orange, CA, USA. Patients were included in the study if they provided written/signed informed consent.

\section{Demographic, Clinical and Laboratory Measurements}

MADRAD study coordinators collected baseline data on demographic and clinical measures. Data on body mass index (BMI), using post-dialysis weight, were primarily obtained from the electronic records of a large dialysis organization, and supplemented with available BMI levels collected by MADRAD study coordinators. Additional details about body anthropometry ascertainment and depression and quality of life measures have been previously reported $[29,30]$.

Using large dialysis organization electronic records, we extracted routine laboratory measurements obtained closest to the blood draw dates for baseline 2-AG or AEA in all analyses. For laboratory analyses, predialysis non-fasting blood samples were drawn using standardized techniques and measured using automated and standardized methods at a central laboratory in Deland, FL, typically within $24 \mathrm{~h}$. We calculated dialysis vintage for MHD patients 
as the time between the dates of the patient's first dialysis treatment and serum AG or AEA measurement. The presence of diabetes as a preexisting comorbidity was determined at the time of study entry by a combination of patient self-reported history and International Classification of Diseases- 9 codes by MADRAD study coordinators.

\section{Serum Samples and Analyses}

Serum concentrations of interleukin (IL)-6 were measured using ELISA assay kits (R\&D systems, Minneapolis, MN, USA, and Affymetrix ThermoFisher Scientific) per manufacturer's protocol. For ECB analyses, non-fasting serum was obtained from patients before weekly dialysis sessions, coinciding with routine blood tests performed at the outpatient dialysis facilities, and frozen at $-80^{\circ} \mathrm{C}$ until analysis. Analysis of 2-AG and AEA was performed using ultra performance liquid chromatography - tandem mass spectrometry (UPLC/MS/MS) as previously described [30]. For the assay, the established lower limit of quantitation (signal-to-noise ratio of N10) of analytes using our optimized UPLC/MS/MS methods were as follows: $2-\mathrm{AG}, 0.5 \mathrm{pmol}$; AEA, 0.008 pmol [31]. For further details, please see the online supplementary Material (for all online suppl. material, see www. karger.com/doi/10.1159/000505444.

\section{Exposure and Outcome Ascertainment}

The primary exposures of interest were continuous serum 2-AG and AEA. We also created categorical exposure variables of serum 2-AG and AEA by dichotomizing serum 2-AG and AEA levels at their median values $(<32.5$ and $\geq 32.5 \mathrm{pmol} / \mathrm{mL} ;<1.06$ and $\geq 1.06 \mathrm{pmol} / \mathrm{mL}$ respectively).

The primary outcome was 12 -month all-cause mortality. Patients were followed from date of measured serum 2-AG or serum AEA to death, transplantation, loss-to-follow-up, end-of-study period (June 30, 2018 for both) or 12-month follow-up, whichever occurred first. Information on mortality and censored events was collected every 6 months by MADRAD study coordinators and reviewed by MADRAD study nephrologists (C.M.R. and K.K.-Z.).

\section{Statistical Analysis}

Baseline patient characteristics are presented according to $2-\mathrm{AG}$ and AEA categories. We used mean \pm SD or median (interquartile range) for continuous variables and proportions for categorical variables, where appropriate. Outliers less than the 0.5 th or greater than the 99.5th percentiles of laboratory data were removed and replaced with their respective lower or upper threshold values. Most often 2 or less lab values were updated, with the exception of biceps skin fold and BMI, which had 4 and 3 values replaced respectively. Absolute standardized differences were used for comparison of baseline characteristics between 2-AG and AEA categories, separately. Imbalance of patient characteristics across exposure categories was defined as an absolute value of the standardized difference $>0.20$. We tested the normal distributions of serum 2-AG and AEA using Shapiro-Wilk tests.

We used Spearman's rank correlation coefficients (Rho) to evaluate the relationship between clinical, laboratory, quality of life and depression measures with non-normally distributed serum 2-AG and AEA levels.

Using Cox proportional hazards models with restricted cubic spline functions, we examined the associations of continuous serum 2-AG and AEA levels with 12-month all-cause mor- tality using 4 adjustment models: (1) Model 1 - Unadjusted; (2) Model 2 - case-mix adjusted (age, sex, race and ethnicity); (3) Model 3 - Model 2 + diabetes and dialysis vintage; and (4) Model 4 - Model 3 + IL-6. Correlation analyses were performed with model 3 adjustment. As secondary analyses, associations of serum 2-AG and AEA as categorical variables with 12-month all-cause mortality were also assessed across the 4 adjustment models.

Missing data for IL-6 in the 2-AG and AEA cohorts (20 and $25 \%$ of data, respectively) were imputed by the mean. Two-sided $p$ values $<0.05$ were considered statistically significant. All statistical analyses were performed with SAS, version 9.4 (SAS Institute Inc., Cary, NC, USA) and STATA MP version 13.1 (StataCorp, College Station, TX, USA).

\section{Results}

\section{Patient Characteristics}

The final study populations included 400 patients with serum 2-AG measurements and 436 patients with serum AEA measurements. Table 1 shows the baseline characteristics of 400 patients in the 2-AG cohort and 436 patients in the AEA cohort respectively. Among $400 \mathrm{MHD}$ patients, the mean \pm SD age was $55 \pm 14$ years; $45 \%$ were female, $29 \%$ were African-American and $54 \%$ were diabetic. Patients with higher serum 2-AG concentrations were more likely to be African-American, have higher levels of BMI, total iron-binding capacity, triglycerides and cholesterol, but lower high-density lipoprotein-cholesterol (HDL-C; absolute standardized difference $>0.2$ ). Of the 436 patients with serum AEA levels, the mean \pm SD age was $55 \pm 14$ years; $44 \%$ were female, $30 \%$ were African-American and 54\% were diabetic. Compared to patients with lower serum AEA levels, patients with higher serum AEA levels were more likely to be older and have higher IL-6 concentrations, but lower levels of very lowdensity lipoprotein-cholesterol (VLDL-C) and creatinine.

\section{Correlations of Serum 2-AG and AEA with Clinical and Laboratory Measures}

We observed correlations between serum 2-AG and all lipids after adjustment for case-mix plus diabetes and dialysis vintage variables. Spearman correlation coefficients for lipoprotein(a)-cholesterol, low-density lipoprotein-cholesterol and total cholesterol were weak (Spearman's rho coefficients, $-0.10,0.12$, and 0.15 respectively), whereas HDL-C, VLDL-C and triglycerides modestly correlated with serum $2-\mathrm{AG}$ concentrations (Spearman's rho coefficients, $-0.34,0.41$, and 0.47 , respectively; Table 2). Body anthropometric measures in-
Moradi et al. 
Table 1. Baseline characteristics of MHD patients according to serum 2-AG and AEA categories

\begin{tabular}{|c|c|c|c|c|c|c|c|c|}
\hline Variable & total & $<32.5$ & $\geq 32.5$ & $\begin{array}{l}\text { standardized } \\
\text { differences }\end{array}$ & total & $<1.06$ & $\geq 1.06$ & $\begin{array}{l}\text { standardized } \\
\text { differences }\end{array}$ \\
\hline$n(\%)$ & 400 & $200(50)$ & $200(50)$ & & 436 & $217(50)$ & $219(50)$ & \\
\hline Age, years & $55 \pm 14$ & $54 \pm 15$ & $56 \pm 13$ & 0.14 & $55 \pm 14$ & $53 \pm 15$ & $57 \pm 14$ & 0.24 \\
\hline Gender, female & 45 & 41 & 49 & 0.15 & 44 & 42 & 46 & 0.08 \\
\hline African-American & 29 & 24 & 33 & 0.20 & 30 & 22 & 38 & 0.37 \\
\hline Asian & 7 & 9 & 6 & -0.10 & 7 & 10 & 4 & -0.26 \\
\hline Other & 1 & 2 & 0 & -0.20 & 1 & 1 & 1 & -0.04 \\
\hline Hispanic ethnicity & 56 & 62 & 50 & -0.24 & 54 & 61 & 48 & -0.26 \\
\hline Diabetes & 54 & 52 & 56 & 0.09 & 54 & 49 & 59 & 0.20 \\
\hline AV fistula & 78 & 83 & 74 & -0.21 & 78 & 85 & 71 & -0.32 \\
\hline $\mathrm{BMI}, \mathrm{kg} / \mathrm{m}^{2}$ & $27.7 \pm 6.7$ & $26.5 \pm 6.2$ & $28.8 \pm 6.9$ & 0.35 & $27.7 \pm 6.5$ & $27.5 \pm 5.9$ & $28.0 \pm 7.0$ & 0.07 \\
\hline
\end{tabular}

Data are presented as percentages, mean \pm SD or median (IQR), where appropriate.

Percentages may not add up to 100 as a result of rounding. Data are not shown for unknown access type ( $<1 \%$ of entire study cohort). Baseline characteristics were compared between 2-AG and AEA categories with standardized differences ( $\geq 2$ considered statistically significant).

AV, arteriovenous; MHD, maintenance hemodialysis; AEA, anandamide; 2-AG, 2-arachidonoyl-sn-glycerol; BMI, body mass index; $\mathrm{IQR}$, interquartile range.

cluding BMI, average triceps skin fold and average biceps skin fold correlated positively with serum 2-AG levels (Spearman's rho coefficients, $0.18,0.22$, and 0.23 , respectively). Results of Spearman correlation coefficients of 2-AG with additional laboratory tests, quality of life and depression data are presented in online supplementary Table S1. Serum 2-AG levels significantly correlated with unsaturated iron binding capacity, total body water, and patient weight.

Spearman correlation coefficients between serum AEA and creatinine, triglycerides and VLDL-C were around -0.1 (Spearman's rho coefficients, $-0.12,-0.13$, and -0.18 respectively; Table 2) after adjustment for case-mix plus diabetes and dialysis vintage covariates, whereas, IL-6 positively correlated with serum AEA concentrations (Spearman's rho coefficient, 0.18). Body anthropometric data did not correlate with serum AEA levels. In online supplementary Table S2, additional Spearman correlation coefficients of AEA and other relevant laboratory tests, quality of life and depression data are reported.
Associations of Serum 2-AG and AEA with 12-Month All-Cause Mortality Risk

Among 400 patients in whom serum 2-AG levels were measured, 43 death events occurred during 1 year of follow-up with an incidence rate (95\% CI) of 11.7 (8.2-15.2). Restricted cubic splines showed that patients with serum 2 -AG levels $>32.5 \mathrm{pmol} / \mathrm{mL}$ (reference) had lower 12-month mortality risk across adjustment models 2-4 (Fig. 1). In secondary analyses with serum 2-AG as a categorical exposure variable, patients with high serum 2 -AG $(\geq 32.5 \mathrm{pmol} / \mathrm{mL})$ had lower 12 -month all-cause mortality risk compared to the reference group of low serum $2-\mathrm{AG}(<32.5 \mathrm{pmol} / \mathrm{mL})$ in models 3 and 4 (hazard ratios [95\% CI] 0.52 [0.28-0.99] and 0.52 [0.28-0.98] pmol/mL respectively; online suppl. Fig. S1, Table S3).

In $436 \mathrm{MHD}$ patients with serum AEA levels, 47 death events occurred during 1 year of follow-up with an incidence rate of 11.7 (8.4-15.1). Results for serum AEA using restricted cubic spline models suggested that higher serum AEA levels trended towards higher 12-month mortality risk across all models (Fig. 2). However, we 
Table 2. Unadjusted and adjusted Spearman's rank correlation coefficients (Rho) between serum 2-AG and AEA levels and laboratory and clinical measures in maintenance hemodialysis patients

\begin{tabular}{|c|c|c|c|c|c|c|c|c|}
\hline \multirow[t]{3}{*}{ Variable } & \multicolumn{4}{|c|}{ Serum 2-AG, $\mathrm{pmol} / \mathrm{mL}$} & \multicolumn{4}{|c|}{ Serum AEA, $\mathrm{pmol} / \mathrm{mL}$} \\
\hline & \multicolumn{2}{|c|}{ unadjusted } & \multicolumn{2}{|c|}{ adjusted* } & \multicolumn{2}{|c|}{ unadjusted } & \multicolumn{2}{|c|}{ adjusted* } \\
\hline & rho & $p$ value & rho & $p$ value & rho & $p$ value & rho & $p$ value \\
\hline \multicolumn{9}{|l|}{ Laboratory tests } \\
\hline Albumin, g/dL & -0.02 & 0.73 & 0.03 & 0.58 & -0.15 & 0.006 & -0.07 & 0.21 \\
\hline Creatinine, $\mathrm{mg} / \mathrm{dL}$ & 0.03 & 0.59 & 0.07 & 0.21 & -0.14 & 0.007 & -0.12 & 0.02 \\
\hline Ferritin, ng/mL & 0.03 & 0.59 & 0.03 & 0.57 & -0.03 & 0.60 & -0.03 & 0.54 \\
\hline $\mathrm{TIBC}, \mathrm{mg} / \mathrm{dL}$ & 0.18 & 0.001 & 0.22 & $<0.0001$ & -0.05 & 0.37 & -0.006 & 0.92 \\
\hline PTH, pg/mL & 0.004 & 0.95 & -0.01 & 0.83 & -0.02 & 0.67 & -0.02 & 0.76 \\
\hline \multicolumn{9}{|l|}{ Lipids } \\
\hline VLDL-C, mg/dL & 0.35 & $<0.0001$ & 0.41 & $<0.0001$ & -0.23 & $<0.0001$ & -0.18 & 0.0002 \\
\hline Triglycerides, mg/dL & 0.43 & $<0.0001$ & 0.47 & $<0.0001$ & -0.14 & 0.003 & -0.13 & 0.009 \\
\hline Cholesterol, mg/dL & 0.13 & 0.01 & 0.15 & 0.004 & 0.02 & 0.74 & 0.002 & 0.97 \\
\hline HDL-C, mg/dL & -0.29 & $<0.0001$ & -0.34 & $<0.0001$ & 0.10 & 0.04 & 0.07 & 0.15 \\
\hline LDL-C, mg/dL & 0.08 & 0.11 & 0.12 & 0.02 & 0.04 & 0.43 & 0.04 & 0.37 \\
\hline $\mathrm{LPA}-\mathrm{C}, \mathrm{mg} / \mathrm{dL}$ & -0.02 & 0.65 & -0.10 & 0.04 & 0.10 & 0.05 & -0.006 & 0.91 \\
\hline NHDL, mg/dL & 0.23 & $<0.0001$ & 0.27 & $<0.0001$ & -0.04 & 0.36 & -0.04 & 0.37 \\
\hline IL-6, pg/mL & -0.03 & 0.63 & -0.06 & 0.32 & 0.19 & 0.0005 & 0.18 & 0.001 \\
\hline $\mathrm{BMI}, \mathrm{kg} / \mathrm{m}^{2}$ & 0.19 & 0.0002 & 0.18 & 0.0005 & 0.05 & 0.28 & -0.005 & 0.92 \\
\hline \multicolumn{9}{|l|}{ Body anthropometry measures } \\
\hline Biceps skin fold, mm & 0.22 & $<0.0001$ & 0.23 & $<0.0001$ & -0.05 & 0.35 & -0.06 & 0.28 \\
\hline Triceps skin fold, mm & 0.21 & 0.0001 & 0.22 & 0.0002 & -0.06 & 0.30 & -0.09 & 0.13 \\
\hline Mid-arm muscle circ., mm & -0.007 & 0.91 & 0.002 & 0.97 & 0.09 & 0.10 & 0.05 & 0.33 \\
\hline Mid-arm circ., mm & 0.15 & 0.007 & 0.15 & 0.008 & 0.07 & 0.22 & 0.02 & 0.74 \\
\hline NIR body fat, $\%$ & 0.17 & 0.002 & 0.16 & 0.006 & -0.01 & 0.85 & -0.05 & 0.33 \\
\hline
\end{tabular}

* Results were adjusted for age, gender, race, ethnicity, diabetes and dialysis vintage.

2-AG, 2-arachidonoyl-sn-glycerol; AEA, anandamide; circ., circumference; HDL-C, high-density lipoprotein-cholesterol; IL-6, interleukin-6; LDL-C, low-density lipoprotein-cholesterol; LPA-C, lipoprotein(a)-cholesterol; NHDL, non-high-density lipoprotein; NIR, near-infrared; PTH, parathyroid hormone; TIBC, total iron-binding capacity; VLDL-C, very low-density lipoprotein-cholesterol; BMI, body mass index.

found no associations between serum AEA as a categorical variable and 12-month mortality risk (online suppl. Fig. S2, Table S4).

\section{Discussion}

It has been shown that non-traditional risk factors such as impaired energy metabolism, PEW and cachexia make a substantial contribution to the disproportionately elevated risk of death in patients with ESRD being treated with MHD. In this regard, activation of the ECB system results in increased energy intake, generation and storage and overactivity of this system (as indicated by elevated circulating ECB levels) has been shown to be associated with obesity and hyperlipidemia [20]. However, the association of circulating ECB levels with mortality has not been evaluated in patients with ESRD. In this study, we confirmed our previous findings in a larger set of MHD patients and found that serum levels of a major ECB ligand, 2-AG, positively correlate with higher serum triglyceride levels, increased BMI and higher body mass [30]. These findings are consistent with available literature on the role of circulating ECBs in pathogenesis of obesity and metabolic syndrome. However, we also found that higher serum 2-AG levels were associated with a significant reduction in the risk of all-cause mortality in MHD patients. The latter findings remained robust after adjustment for several important covariates including diabetes, dialysis vintage and serum IL-6 levels. Additionally, these observations were unique to $2-\mathrm{AG}$ given that similar findings were not noted when evaluating the association of serum AEA levels, another major ECB ligand, with laboratory and clinical outcomes. In fact, higher se- 


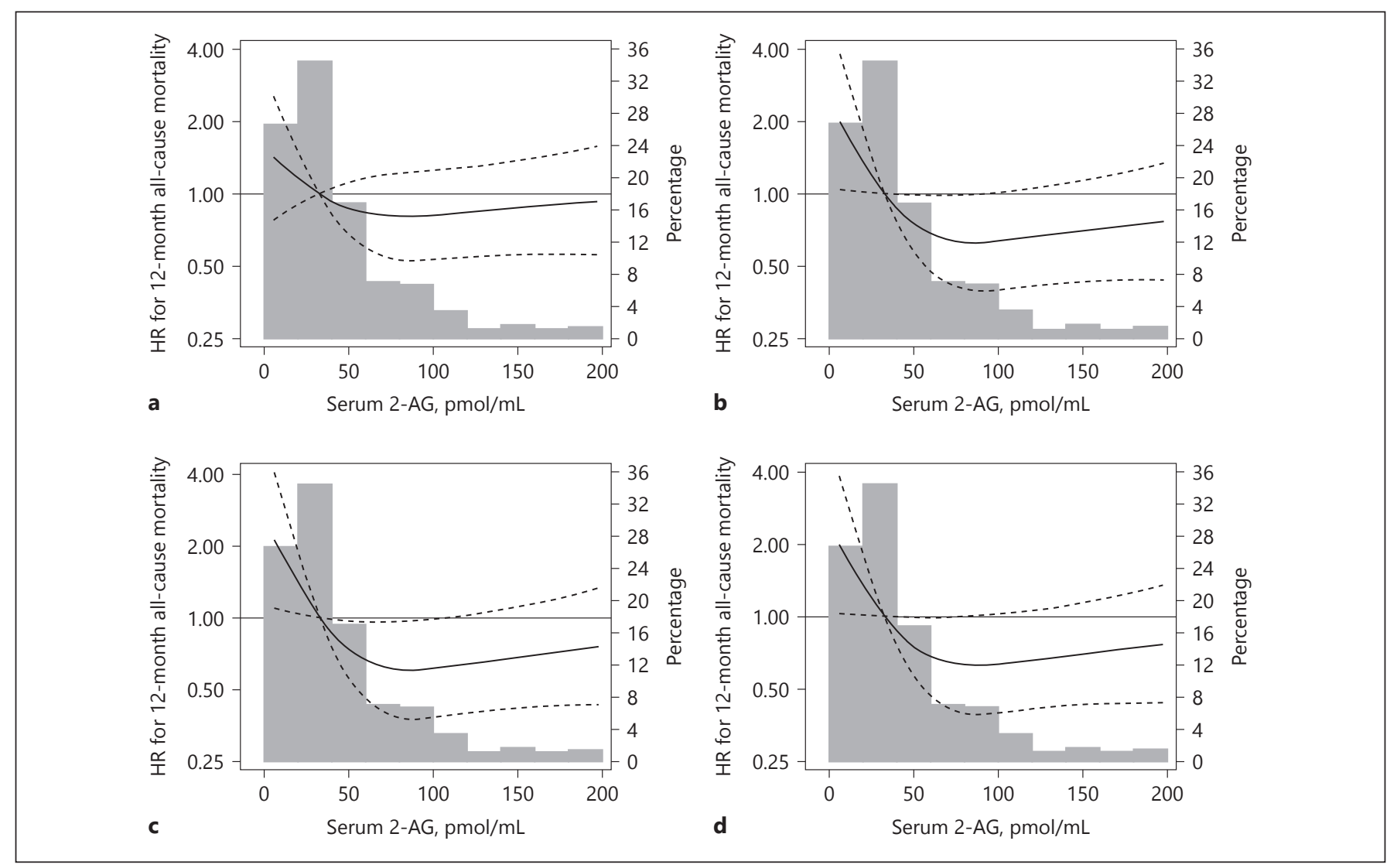

Fig. 1. Restricted cubic splines of the association between serum 2-AG and 12-month all-cause mortality among $400 \mathrm{MHD}$ patients. Splines were adjusted for covariates in models 1-4 as follows: (a) model 1 (unadjusted); (b) model 2 (age, gender, race and

rum AEA levels correlated with reduced concentrations of triglyceride-rich lipoproteins (VLDL) and increased serum concentrations of the pro-inflammatory cytokine, IL-6. In addition, higher serum AEA levels were not associated with improved survival and there was a trend toward worse outcomes in some of these analyses (Fig. 2).

While the exact mechanisms underlying these results remain to be elucidated, several aspects of these findings can be explained in the context of the mechanism of action of the ECB system and observational data from MHD patients. As mentioned earlier, there is abundant evidence linking overactivity of the ECB system to obesity and elevated triglyceride levels. While the latter findings may be associated with adverse outcomes in the general population, their association with outcomes is not as well-established in patients at high risk for PEW and cachexia such as the ESRD population. In fact, there is evidence that obesity and hypertriglyceridemia are associated with a lower risk of mortality in some MHD patients ethnicity); (c) model 3 (model $2+$ diabetes and dialysis vintage); and (d) model 4 (model $3+$ IL-6). Solid and dotted lines represent hazard ratios and $95 \%$ CIs respectively. $\mathrm{HR}$, hazard ratio; $2-\mathrm{AG}$, arachidonoyl-sn-glycerol.

and these paradoxical associations may be partly related to the lower risk of cachexia in these patient subsets [8$10,32]$. Therefore, it can be speculated that in MHD patients, higher circulating levels of 2-AG and increased ECB system activity are associated with improved energy production and preservation. This manifests clinically with higher BMI and serum triglycerides, and reduced risk of cachexia and ultimately decreased risk of death (Fig. 3).

There are some mechanistic pathways that may support this theory. For instance, it has been demonstrated that CKD is associated with the wasting of adipose tissue and skeletal muscle through enhanced fat and protein catabolism [33]. This is partly attributed to increased expression of thermogenic genes in fat tissue and "browning" of white adipocytes resulting in increased thermogenesis and inefficient energy expenditure $[15,34]$. In this regard, 2-AG-mediated activation of the ECB system has been shown to prevent expression of thermogenic genes 


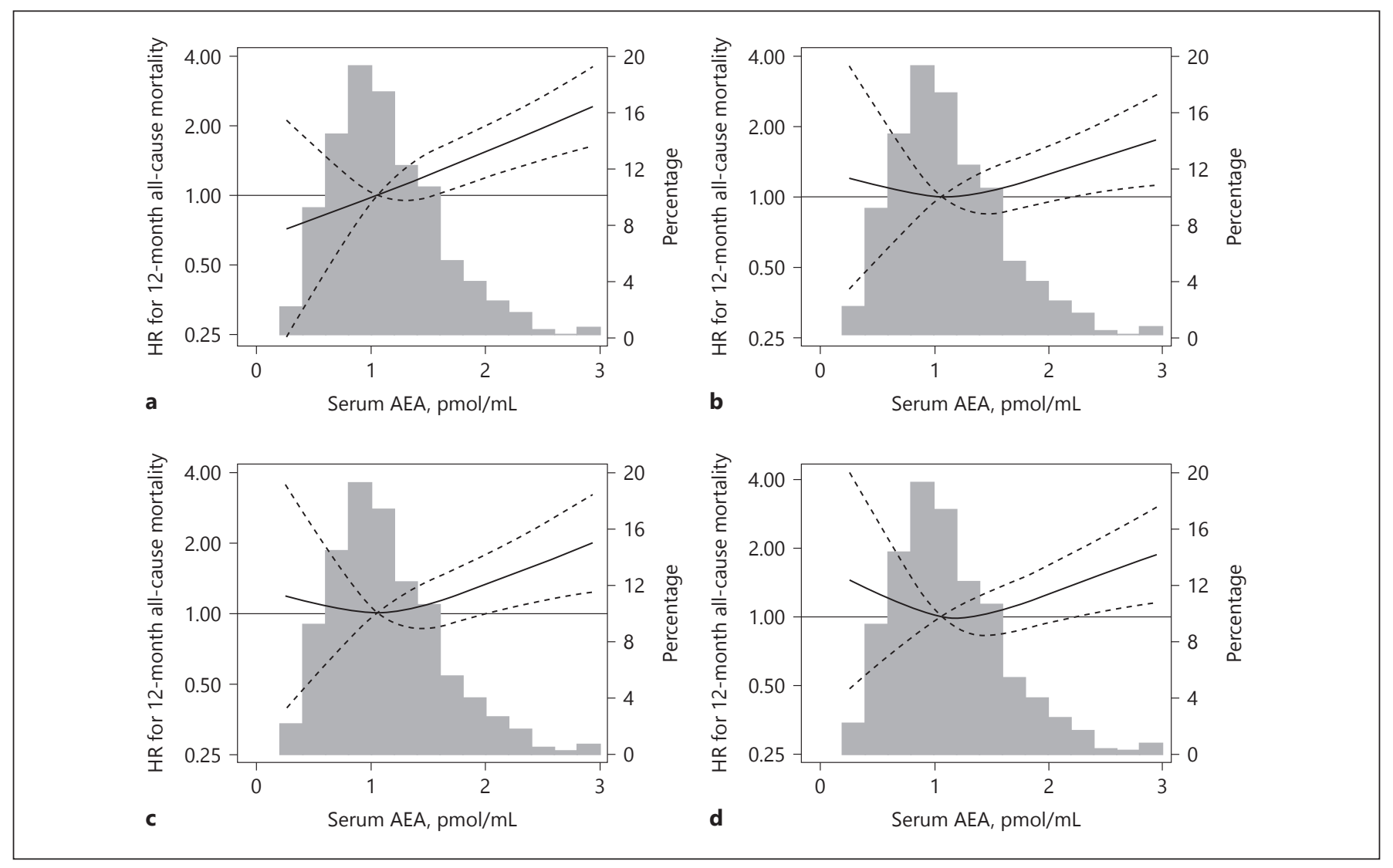

Fig. 2. Restricted cubic splines of the association between serum AEA and 12-month all-cause mortality among 436 MHD patients. Splines were adjusted for covariates in models 1-4 as follows: (a) model 1 (unadjusted); (b) model 2 (age, gender, race and ethnici-

and "browning" of white adipose tissue $[35,36]$. Therefore, it is possible that increased serum 2-AG levels in ESRD prevent CKD-associated inefficient energy metabolism, which can increase the risk of cachexia and lead to poor outcomes. While the possibility that obesity and hypertriglyceridemia directly contribute to increasing serum 2-AG levels cannot be excluded, there is also evidence that activation of the EC system via 2-AG may play a causative role in elevated triglyceride levels [36]. This is mediated via activation of $\mathrm{CB}_{1} \mathrm{R}$, which leads to increased synthesis of fatty acids (through stimulation of the sterol regulatory element binding protein $1 \mathrm{c}$ [SREBP1c] pathway) and decreased fatty acid $\beta$-oxidation (downregulation of the peroxisome proliferator activated receptor- $\alpha$ pathway) [37]. Therefore, it is possible that increased energy production, in the form of fatty acids and elevated triglycerides, may be driven by higher 2-AG levels (Fig. 3). However, these notions remain speculative at this time and larger observational and mechanistic studies are ty); (c) model 3 (model $2+$ diabetes and dialysis vintage); and (d) model 4 (model 3 + IL-6). Solid and dotted lines represent hazard ratios and 95\% CIs, respectively. $\mathrm{HR}$, hazard ratio; AEA, anandamide.

needed to confirm these hypotheses and explore other potential pathways which can explain our findings.

It is interesting to note that while 2-AG and AEA are both considered key ligands of the ECB system that bind $\mathrm{CB}$ receptors with high affinity, the correlation of circulating levels of these lipid-derived mediators with laboratory and clinical indices and their association with all-cause mortality is considerably different. Similar findings have also been reported by other investigators and these differential effects have been partly explained in the context of functional selectively (also known as ligand bias) [38-40]. In this regard, it is well known that $\mathrm{CB}$ receptors are members of the G-protein-coupled receptors whose activation is associated with recruitment of various G-proteins and a series of downstream effects $[41,42]$. However, there is growing evidence that the recruitment of these G-proteins is highly dependent and driven by the ligand which is activating the $\mathrm{CB}_{1} \mathrm{R}$, a concept known as functional selectivity $[41,42]$. Hence, while $2-A G$ activation of CB receptors 


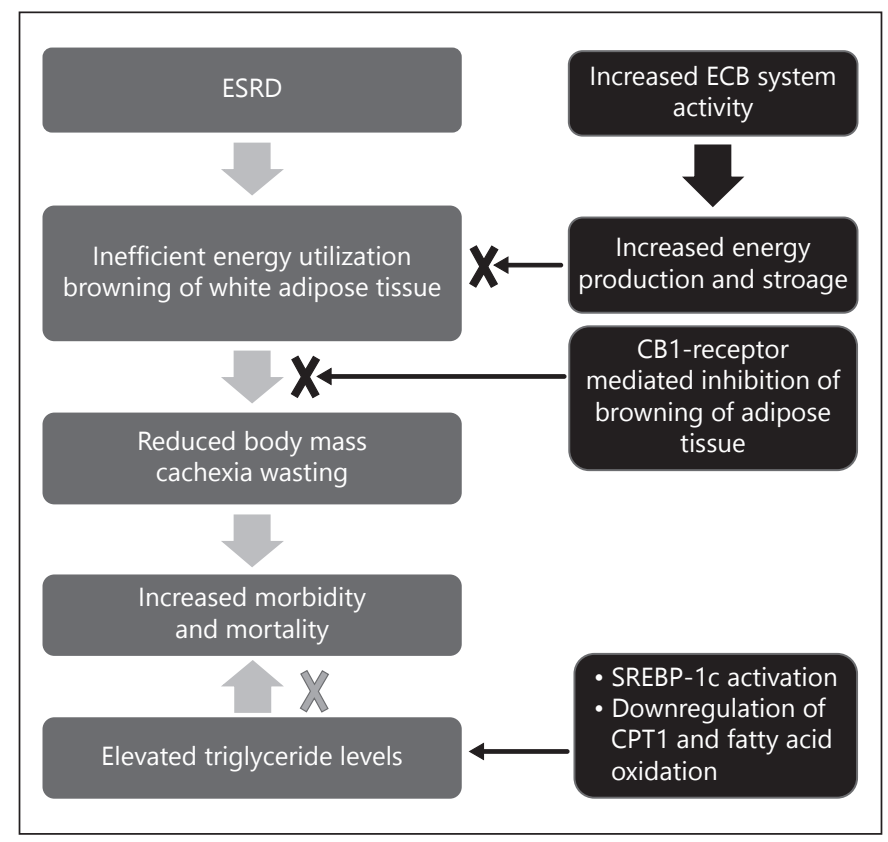

Fig. 3. Potential impact of increased serum 2-AG levels in patients with ESRD on MHD. Elevated circulating levels of 2-AG and overactivity of the ECB system can be associated with reduced energy loss (decreased browning of white adipose tissue) and enhanced energy production (increased fatty acid and triglyceride generation). The latter effects can help reduce the risk of cachexia and mortality in ESRD patients on hemodialysis. CB-1, cannabinoid 1 receptor; $\mathrm{CPT} 1$, carnitine palmitoyltransferase-1; ECB, endocannabinoid; ESRD, end-stage renal disease; SREBP-1c, sterol regulatory element binding.

may be associated with recruitment of one set of mediators resulting in a given effect, activation by other mediators (such as tetrahydrocannabinol or AEA) can recruit a different group of molecules leading to a different outcome $[42,43]$. For instance, it has been shown that changes in circulating levels of AEA are driven by hunger and respond to food in a manner consistent with homeostatic (hunger-driven) feeding. In contrast, the response of circulating 2-AG levels to food is driven by a meal's perceived hedonic value and 2-AG is involved in reward-driven feeding [44-46]. In a study similar to ours, Cote et al. [47] found that circulating 2-AG but not AEA levels correlated positively with BMI, fasting plasma triglycerides and negatively with HDL-C. It was argued that these differential correlations are supported by evidence that 2-AG is the more effective activator of ECB system [48]. Furthermore, it has been shown that AEA can bind to several other targets, thereby mediating differential effects [49]. Therefore, there is evidence that ECB ligands can facilitate differential effects under different conditions.
Several limitations of our study need to be acknowledged. The present findings should be qualified given the observational nature of our study design, and future mechanistic studies are needed to determine if a causal link between circulating 2-AG levels and reduced mortality exists. While another limitation of our study is the small sample size, it should be noted that this is one of the largest studies of circulating ECBs levels in a single patient cohort. Nevertheless, larger studies are needed to confirm and build on our findings. Although we adjusted for some potential confounders such as diabetes and inflammation (IL-6), given lack of data regarding hospitalization and infections, residual confounding cannot be excluded. Additionally, our patient cohort lacked detailed nutritional data (such as food intake) and information on visceral adipose tissue and therefore we cannot measure or rule out a potential impact from these factors in the associations observed in this study. Future studies will need to examine these important endpoints in the context of circulating ECBs in MHD patients. Finally, we used nonfasting serum for all analyses and hence cannot rule out the potential impact of food intake on the levels of circulating ECBs. It has been reported, however, that circulating levels of 2-AG are not affected by feeding [46] or intraduodenal administration of a lipid emulsion [50]. In addition, given that we used non-fasting serum for all of our analyses, variability of results based on fasting state of the patients is less likely.

In conclusion, we found that circulating levels of 2-AG, a major ECB ligand, may play an important role in determining body mass and the risk of mortality in ESRD patients treated with MHD. These observations were unique to $2-A G$ as similar findings were not obtained with serum AEA, the other major ligand of the ECB system. Future studies need to confirm these findings, investigate the mechanisms responsible for these associations, and examine the modulation of the ECB system (especially 2-AG) as a potential target for therapy in MHD patients.

\section{Acknowledgments}

The project described was supported by the National Center for Research Resources and the National Center for Advancing Translational Sciences, National Institutes of Health, through Grant UL1 TR001414. The content is solely the responsibility of the authors and does not necessarily represent the official views of the $\mathrm{NIH}$. We are also grateful to UC Irvine Institute for Clinical and Translational Science for their support. H.M. is supported by a career development award from the Office of Research and Development of the Department of Veterans Affairs 1 IK CX 001043-01A2. E.S. is supported by a career development award from the Office 
of Research and Development of the Department of Veterans Affairs (IK2-CX001266-01). KKZ is supported by NIH (NIDDK) grant K24-DK091419, and philanthropic grants from Mr. Harold Simmons, Mr. Louis Chang, Joseph Lee, and AVEO, Inc. C.M.R. is supported by the NIH (NIDDK) grant K23-DK102903. The NVD laboratory is supported by NIH grants R01-DK119498 and L30-DK114978 (NIDDK), and R21-AI135500 (NIAID). H.M., E.S., and K.K.-Z. are employees of the US Department of Veterans Affairs. The opinions expressed in this article are those of the authors and do not represent the views of the US Department of Veterans Affairs or the US government.

\section{Disclosure Statement}

H.M. has received funding from the NIH, VA ORD, Amgen and Novartis. K.K.-Z. has received honoraria and/or support from Abbott, Abbvie, Alexion, Amgen, American Society of Nephrology, Astra-Zeneca, AVEO, Chugai, DaVita, Fresenius, Genetech,
Haymarket Media, Hospira, Kabi, Keryx, National Institutes of Health, National Kidney Foundation, Relypsa, Resverlogix, Sanofi, Shire, Vifor, ZS-Pharma. K.K.-Z., H.M., and D.P. declare the following conflict of interest: they are inventors in a patent application filed by the University of California, Irvine, which protects certain aspects of the work described in the present article.

\section{Author Contributions}

H.M., D.P., and K.K.-Z. research idea and study design. H.M., C.P., E.S., A.S.Y., and C.M.R. data acquisition. H.M., D.A.A., C.P., and E.S. data analysis/interpretation. H.M., C.P., and E.S. statistical analysis. D.P., K.K.-Z., N.D.V., and N.V.D. supervision or mentorship. Each author contributed important intellectual content during manuscript drafting or revision, accepts personal accountability for the author's own contributions, and agrees to ensure that questions pertaining to the accuracy or integrity of any portion of the work are appropriately investigated and resolved.

\section{References}

1 Saran R, Robinson B, Abbott KC, Agodoa LY, Bragg-Gresham J, Balkrishnan R, et al. Us renal data system 2018 annual data report: epidemiology of kidney disease in the united states. Am J Kidney Dis. 2019 Mar;73(3S1):A7-8.

2 McCullough KP, Morgenstern H, Saran R, Herman WH, Robinson BM. Projecting esrd incidence and prevalence in the united states through 2030. J Am Soc Nephrol. 2019 Jan; 30(1):127-35.

3 Kovesdy CP, Kalantar-Zadeh K. Enter the dragon: a Chinese epidemic of chronic kidney disease? Lancet. 2012 Mar;379(9818):783-5.

4 Zhang L, Wang F, Wang L, Wang W, Liu B, Liu J, et al. Prevalence of chronic kidney disease in China: a cross-sectional survey. Lancet. 2012 Mar;379(9818):815-22.

5 Us renal data system. Excerpts from the usrds. Annual data report: Atlas of end-stage renal disease in the united states. 2012.

6 Moradi H, Streja E, Vaziri ND. ESRD-induced dyslipidemia-Should management of lipid disorders differ in dialysis patients? Semin Dial. 2018 Jul;31(4):398-405.

7 Chang TI, Streja E, Ko GJ, Naderi N, Rhee $\mathrm{CM}$, Kovesdy CP, et al. Inverse association between serum non-high-density lipoprotein cholesterol levels and mortality in patients undergoing incident hemodialysis. J Am Heart Assoc. 2018 Jun;7(12):7.

8 Naderi N, Kleine CE, Park C, Hsiung JT, Soohoo M, Tantisattamo E, et al. Obesity paradox in advanced kidney disease: from bedside to the bench. Prog Cardiovasc Dis. 2018 Jul - Aug;61(2):168-81.

9 Kleine CE, Moradi H, Streja E, Kalantar-Zadeh K. Racial and ethnic disparities in the obesity paradox. Am J Kidney Dis. 2018 Nov;72(5 Suppl 1):S26-32.
10 Chang TI, Streja E, Soohoo M, Kim TW, Rhee $\mathrm{CM}$, Kovesdy CP, et al. Association of serum triglyceride to hdl cholesterol ratio with allcause and cardiovascular mortality in incident hemodialysis patients. Clin J Am Soc Nephrol. 2017 Apr;12(4):591-602.

11 Obi Y, Qader H, Kovesdy CP, Kalantar-Zadeh $\mathrm{K}$. Latest consensus and update on proteinenergy wasting in chronic kidney disease. Curr Opin Clin Nutr Metab Care. 2015 May; 18(3):254-62.

12 Ikizler TA, Cano NJ, Franch H, Fouque D, Himmelfarb J, Kalantar-Zadeh K, et al.; International Society of Renal Nutrition and Metabolism. Prevention and treatment of protein energy wasting in chronic kidney disease patients: a consensus statement by the International Society of Renal Nutrition and Metabolism. Kidney Int. 2013 Dec;84(6):1096107.

13 Mak RH, Ikizler AT, Kovesdy CP, Raj DS, Stenvinkel P, Kalantar-Zadeh K. Wasting in chronic kidney disease. J Cachexia Sarcopenia Muscle. 2011 Mar;2(1):9-25.

14 Beddhu S, Chen X, Wei G, Raj D, Raphael KL, Boucher R, et al. Associations of protein-energy wasting syndrome criteria with body composition and mortality in the general and moderate chronic kidney disease populations in the united states. Kidney Int Rep. 2017 May;2(3):390-9.

15 Thomas SS, Mitch WE. Parathyroid hormone stimulates adipose tissue browning: a pathway to muscle wasting. Curr Opin Clin Nutr Metab Care. 2017 May;20(3):153-7.

16 Silvestri C, Di Marzo V. The endocannabinoid system in energy homeostasis and the etiopathology of metabolic disorders. Cell Metab. 2013 Apr;17(4):475-90.
17 DiPatrizio NV, Piomelli D. The thrifty lipids: endocannabinoids and the neural control of energy conservation. Trends Neurosci. 2012 Jul;35(7):403-11.

18 Piomelli D. The endocannabinoid system: a drug discovery perspective. Curr Opin Investig Drugs. 2005 Jul;6(7):672-9.

19 Maccarrone M, Bab I, Bíró T, Cabral GA, Dey SK, Di Marzo V, et al. Endocannabinoid signaling at the periphery: 50 years after THC. Trends Pharmacol Sci. 2015 May;36(5):27796.

20 Hillard CJ. Circulating endocannabinoids: from whence do they come and where are they going? Neuropsychopharmacology. 2018 Jan;43(1):155-72.

21 Gatta-Cherifi B, Cota D. New insights on the role of the endocannabinoid system in the regulation of energy balance. Int J Obes. 2016 Feb;40(2):210-9.

22 Quercioli A, Pataky Z, Vincenti G, Makoundou V, Di Marzo V, Montecucco F, et al. Elevated endocannabinoid plasma levels are associated with coronary circulatory dysfunction in obesity. Eur Heart J. 2011 Jun;32(11): 1369-78.

23 Di Marzo V. The endocannabinoid system in obesity and type 2 diabetes. Diabetologia. 2008 Aug;51(8):1356-67.

24 Engeli S, Böhnke J, Feldpausch M, Gorzelniak K, Janke J, Bátkai S, et al. Activation of the peripheral endocannabinoid system in human obesity. Diabetes. 2005 Oct;54(10): 2838-43.

25 Després JP, Golay A, Sjöström L; Rimonabant in Obesity-Lipids Study Group. Effects of rimonabant on metabolic risk factors in overweight patients with dyslipidemia. N Engl J Med. 2005 Nov;353(20):2121-34. 
26 Pi-Sunyer FX, Aronne LJ, Heshmati HM, Devin J, Rosenstock J, RIO-North America Study Group; RIO-North America Study Group. Effect of rimonabant, a cannabinoid-1 receptor blocker, on weight and cardiometabolic risk factors in overweight or obese patients: RIO-North America: a randomized controlled trial. JAMA. 2006 Feb;295(7):761-75.

27 Nam DH, Lee MH, Kim JE, Song HK, Kang YS, Lee JE, et al. Blockade of cannabinoid receptor 1 improves insulin resistance, lipid metabolism, and diabetic nephropathy in $\mathrm{db} /$ db mice. Endocrinology. 2012 Mar;153(3): 1387-96.

28 Moradi H, Park C, Igarashi M, Streja E, Argueta DA, Soohoo M, et al. Serum endocannabinoid levels in patients with end-stage renal disease. J Endocr Soc. 2019 Aug;3(10):186980.

29 Rhee CM, Nguyen DV, Moradi H, Brunelli SM, Dukkipati R, Jing J, et al. Association of adiponectin with body composition and mortality in hemodialysis patients. Am J Kidney Dis. 2015 Aug;66(2):313-21.

30 Grams ME, Sang Y, Ballew SH, Carrero JJ, Djurdjev O, Heerspink HJ, et al. Predicting timing of clinical outcomes in patients with chronic kidney disease and severely decreased glomerular filtration rate. Kidney Int. 2018 Jun;93(6):1442-51.

31 Argueta DA, DiPatrizio NV. Peripheral endocannabinoid signaling controls hyperphagia in western diet-induced obesity. Physiol Behav. 2017 Mar;171:32-9.

32 Doshi M, Streja E, Rhee CM, Park J, Ravel VA, Soohoo M, et al. Examining the robustness of the obesity paradox in maintenance hemodialysis patients: a marginal structural model analysis. Nephrol Dial Transplant. 2016 Aug; 31(8):1310-9.

33 Oliveira EA, Zheng R, Carter CE, Mak RH. Cachexia/Protein energy wasting syndrome in CKD: causation and treatment. Semin Dial. 2019 Nov;32(6):493-9.
34 Kir S, Komaba H, Garcia AP, Economopoulos KP, Liu W, Lanske B, et al. Pth/pthrp receptor mediates cachexia in models of kidney failure and cancer. Cell Metab. 2016 Feb;23(2):315-23.

35 Tedesco L, Valerio A, Dossena M, Cardile A, Ragni M, Pagano C, et al. Cannabinoid receptor stimulation impairs mitochondrial biogenesis in mouse white adipose tissue, muscle, and liver: the role of eNOS, p38 MAPK, and AMPK pathways. Diabetes. 2010 Nov;59(11): 2826-36.

36 Vaziri ND, Moradi H. Mechanisms of dyslipidemia of chronic renal failure. Hemodial Int. 2006 Jan;10(1):1-7.

37 Osei-Hyiaman D, DePetrillo M, Pacher P, Liu J, Radaeva S, Bátkai S, et al. Endocannabinoid activation at hepatic $\mathrm{CB} 1$ receptors stimulates fatty acid synthesis and contributes to dietinduced obesity. J Clin Invest. 2005 May; 115(5):1298-305.

38 Caraceni P, Viola A, Piscitelli F, Giannone F, Berzigotti A, Cescon M, et al. Circulating and hepatic endocannabinoids and endocannabinoid-related molecules in patients with cirrhosis. Liver Int. 2010 Jul;30(6):816-25.

39 Zelber-Sagi S, Azar S, Nemirovski A, Webb M, Halpern Z, Shibolet O, et al. Serum levels of endocannabinoids are independently associated with nonalcoholic fatty liver disease. Obesity (Silver Spring). 2017 Jan;25(1):94-101.

40 Blüher M, Engeli S, Klöting N, Berndt J, Fasshauer M, Bátkai S, et al. Dysregulation of the peripheral and adipose tissue endocannabinoid system in human abdominal obesity. Diabetes. 2006 Nov;55(11):3053-60.

41 Nogueras-Ortiz C, Yudowski GA. The multiple waves of cannabinoid 1 receptor signaling. Mol Pharmacol. 2016 Nov;90(5):620-6.

42 Ibsen MS, Connor M, Glass M. Cannabinoid $\mathrm{cb} 1$ and $\mathrm{cb} 2$ receptor signaling and bias. Cannabis Cannabinoid Res. 2017 Mar;2(1):48-60.

43 Delgado-Peraza F, Ahn KH, Nogueras-Ortiz C, Mungrue IN, Mackie K, Kendall DA, et al. Mechanisms of Biased $\beta$-Arrestin-Mediated
Signaling Downstream from the Cannabinoid 1 Receptor. Mol Pharmacol. 2016 Jun; 89(6):618-29.

44 Monteleone AM, Di Marzo V, Monteleone P, Dalle Grave R, Aveta T, Ghoch ME, et al. Responses of peripheral endocannabinoids and endocannabinoid-related compounds to hedonic eating in obesity. Eur J Nutr. 2016 Jun; 55(4):1799-805.

45 Monteleone P, Piscitelli F, Scognamiglio P, Monteleone AM, Canestrelli B, Di Marzo V, et al. Hedonic eating is associated with increased peripheral levels of ghrelin and the endocannabinoid 2-arachidonoyl-glycerol in healthy humans: a pilot study. J Clin Endocrinol Metab. 2012 Jun;97(6):E917-24.

46 Gatta-Cherifi B, Matias I, Vallée M, Tabarin A, Marsicano G, Piazza PV, et al. Simultaneous postprandial deregulation of the orexigenic endocannabinoid anandamide and the anorexigenic peptide YY in obesity. Int Obes. 2012 Jun;36(6):880-5.

47 Côté M, Matias I, Lemieux I, Petrosino S, Alméras N, Després JP, et al. Circulating endocannabinoid levels, abdominal adiposity and related cardiometabolic risk factors in obese men. Int J Obes. 2007 Apr;31(4):692-9.

48 Sugiura T, Kobayashi Y, Oka S, Waku K. Biosynthesis and degradation of anandamide and 2-arachidonoylglycerol and their possible physiological significance. Prostaglandins Leukot Essent Fatty Acids. 2002 Feb-Mar; 66(2-3):173-92.

49 Di Marzo V, De Petrocellis L, Fezza F, Ligresti A, Bisogno T. Anandamide receptors. Prostaglandins Leukot Essent Fatty Acids. 2002 Feb-Mar;66(2-3):377-91.

50 Little TJ, Cvijanovic N, DiPatrizio NV, Argueta DA, Rayner CK, Feinle-Bisset C, et al. Plasma endocannabinoid levels in lean, overweight, and obese humans: relationships to intestinal permeability markers, inflammation, and incretin secretion. Am J Physiol Endocrinol Metab. 2018 Oct;315(4):E489-95. 